\title{
MiRNA-I 225 Inhibits Osteosarcoma Tumor Growth and Progression by Targeting YWHAZ
}

This article was published in the following Dove Press journal: OncoTargets and Therapy

\author{
Yubao Gong (D) \\ Zhengren $\mathrm{Wei}^{2}$ \\ Jianguo Liu' \\ 'Department of Orthopedics, The First \\ Hospital of Jilin University, Changchun \\ I3002 I, People's Republic of China; \\ ${ }^{2}$ Department of Pharmacology, Basic \\ Medical School, Jilin University, \\ Changchun I3002I, People's Republic of \\ China
}

Introduction: Osteosarcoma is the most common bone tumor and is characterized by the presence of malignant mesenchymal cells produced in the bone stroma. MiRNAs are known to function as post-transcriptional negative regulators of gene expression. Emerging evidence showed that miR-1225-5P functions as a tumor suppressor in several types of cancers. The detailed mechanisms of which miR-1225-5P suppresses tumor growth are not fully understood. The objective of the present study was to test the hypothesis that miR-1225-5P inhibits osteosarcoma cell growth in vitro and tumor growth in vivo by targeting YWHAZ expression.

Methods: Real-time PCR and Western blot were carried out to test the expression of miR1225-5P and YWHAZ in osteosarcoma cell lines. Luciferase assay was used to demonstrate whether miR-1225-5P targets YWHAZ 3' UTR. To assess the function of miR-1225-5P in human osteosarcoma cell lines, gain-of-function and loss-of-function of miR-1225-5P were performed by transfecting miR-1225-5P mimic or miR-1225-5P inhibitor into osteosarcoma cell lines. Furthermore, cell cycle analysis was performed to elucidate the possible mechanisms of the action of miR-1225-5P and YWHAZ in human osteosarcoma cells. The potential therapeutic effect of miR-1225-5p was tested in human osteosarcoma xenograft mouse model, by intravenous injection of miR-1225-5P into nude mice. Tumor sizes were measured and lung metastasis was counted after the mice were sacrificed.

Results: The expression of miR-1225-5P was inversely correlated with the expression of YWHAZ in human osteosarcoma cell lines. Database search revealed that miR-1225-5P targeted YWHAZ 3' UTR. Transfection of miR-1225-5P mimic downregulated YWHAZ expression, which was demonstrated by real-time PCR, Western blot and luciferase assay. Over-expression of miR-1225-5P reduced human osteosarcoma cell growth, migration and invasion by downregulating YWHAZ expression. Cell growth, migration and invasion were increased by inhibiting miR-1225-5P in human osteosarcoma cells. The inhibition of cell growth, migration and invasion was rescued by over-expression of YWHAZ in osteosarcoma cells. Cell cycle analysis revealed that miR-1225-5P inhibited G1/G0 phase exit. In vivo xenograft model demonstrated that miR-1225-5P inhibited in vivo osteosarcoma tumor growth and lung metastasis.

Conclusion: Our findings suggested that miR-1225-5P inhibits osteosarcoma cell growth in vitro and tumor growth in vivo by targeting YWHAZ. This study suggested that miR1225-5P can serve as a potential therapeutic method for treating osteosarcoma.

Keywords: osteosarcoma, microRNA, miR-1225-5P, YWHAZ, metastasis

\section{Introduction}

Osteosarcoma is rare but is the most common histological form of primary bone cancer. ${ }^{1}$ Most osteosarcomas occur in children and young adults. Teens are the most
Department of Orthopedics, The First Hospital of Jilin University, No. I Xinmin Street, Changchun I3002I, People's

Republic of China

Tel +86I5043039765

Email gongyb@jlu.edu.cn
OncoTargets and Therapy 2021:14 I5-27 
commonly affected age group, but osteosarcoma can develop at any age. ${ }^{1}$ Despite the advances of osteosarcoma treatment in recent years, metastasis remains a hurdle. ${ }^{2}$ The 10-year survival rate for patients with metastatic osteosarcoma is $24.0 \%$ compared with $65.8 \%$ for patients with local/regional disease. ${ }^{2}$

YWHAZ, also known as Tyrosine 3-Monooxygenase/ Tryptophan 5-Monooxygenase Activation Protein Zeta, or $14-3-3 \zeta$, is a member of the 14-3-3 protein family. The 143-3 protein family is a group of highly conserved proteins. They are involved in many vital cellular processes such as metabolism, protein trafficking, signal transduction, apoptosis and cell cycle regulation. Emerging evidence shows that YWHAZ serves a critical role in many different types of tumor progression, such as prostate cancer, ${ }^{3}$ breast cancer, ${ }^{4,5}$ head and neck squamous cell carcinoma, ${ }^{6}$ gastric cancer, ${ }^{7}$ and lung cancer. ${ }^{8}$ Aberrant expression of YWHAZ in cancer cells is believed to serve a critical role in tumorigenesis. ${ }^{3,9-12}$ YWHAZ may inactivate tumor suppressors such as $\mathrm{p} 53^{13}$ and directly bind to PI3 kinase, promote Akt activation and enhance cell survival. ${ }^{14}$ Therefore, targeting YWHAZ as a potential cancer therapeutic method has been proposed.

MicroRNAs are a group of small non-codingRNA molecules that contain about 22 nucleotides, and function in RNA silencing and post-transcriptional regulation of gene expression. ${ }^{15,16}$ Numerous miRNAs have been found differentially expressed in osteosarcoma compared with normal bone tissue. ${ }^{17}$ MicroRNAs have been reported to inhibit cancer cell proliferation by targeting YWHAZ, such as miR-204-5P in esophageal squamous cell carcinoma, ${ }^{18}$ and miR-802 in epithelial ovarian cancer. ${ }^{19}$

In this study, we found that miR-1225-5P negatively regulates YWHAZ expression in osteosarcoma cells and inhibits osteosarcoma cell growth in vitro and in vivo. These findings may provide a new avenue towards osteosarcoma treatment.

\section{Materials and Methods}

\section{Osteosarcoma Cell Lines and Culture}

All osteosarcoma cell lines (HOS, MG63, U2OS Saos-2 and hFOB1.19) used in this study were purchased from ATCC (ATCC.org). All the cells were cultured in RPMI-1640 medium (Hyclone) containing $10 \% \mathrm{FBS}$ (Gibco) at $37^{\circ} \mathrm{C}, 5 \% \mathrm{CO}_{2}$.

\section{Cell Transfection}

HOS or U2OS cells were cultured as described above. Before transfection, the cells were plated in 6-well plates at the density of $5 \times 10^{5}$ cells/well and cultured at $37^{\circ} \mathrm{C}, 5 \% \mathrm{CO}_{2}$ for $16 \mathrm{~h}$. For miRNA transfection, the cells were transfected with irrelevant miRNA control (5'-UUCUCCGAACG UGUCACGUTT-3', $100 \mathrm{pmol} / \mathrm{well}$ ), miR-1225 mimic (5'GUGGGUACGGCCCAGUGGGGGG-3', 100 pmol/well), or miR-1225 inhibitor (5'-CCCCCCACUGGGCCGUAC CCAC-3', $100 \mathrm{pmol} /$ well) by using Lipofectamine 2000 (Life Technologies) and following manufacturer's instructions. For Ywhaz over-expression, the cells were transfected with expression vector containing $Y$ whaz coding sequence, or pcDNA3 vector control $(1.5 \mu \mathrm{g} /$ well). Coding sequence of the Ywhaz gene in the expression vector was confirmed by sequencing (Supplemental data).

\section{RNA Isolation and Real-Time PCR}

To isolate total RNA, cells or tumor tissues were placed in $1 \mathrm{~mL}$ Tryzol reagent (Invitrogen) and homogenized with Fluko homogenizer for $20 \mathrm{~s}$. Total RNA was then isolated using Tryzol reagent and following manufacturers's protocol. First strand cDNA was synthesized using RevertAid First Strand cDNA Synthesis Kit (Fermentas) and following the kit protocol. The first strand cDNA samples were used as a template for quantitative real-time PCR to quantify the expression of mRNA by using SYBR green (Thermofisher) and gene specific primers (listed in Table 1).

\section{Cell Growth Assay with Cell Counting Kit-8 (CCK8)}

Transfected HOS or U2OS osteosarcoma cells were plated in 96-well plates at a density of 3000 cells/well in complete growth medium. The cells were cultured at $37^{\circ} \mathrm{C}, 5 \%$ $\mathrm{CO}_{2}$ for $12,24,48$ and $72 \mathrm{~h}$. CCK8 was diluted in serumfree medium (1:10). At each time point, $100 \mu \mathrm{L}$ of diluted CCK8 was added to each well and incubated at $37^{\circ} \mathrm{C}, 5 \%$ $\mathrm{CO}_{2}$ for $1 \mathrm{~h}$. OD $450 \mathrm{~nm}$ was measured in a plate reader (Pulang New Technology, Beijing).

\section{Wound Healing Assay}

Transfected HOS or U2OS osteosarcoma cells were plated in 6-well plates at a density of $8 \times 10^{5} /$ well in complete growth medium and cultured until confluence. A gap in the cells was created by scratching the cells with a $1000 \mu \mathrm{L}$ tip after removing the growth medium. The loose cells were washed away with phosphate buffered saline (PBS), and the cells were further cultured in complete growth medium for 12 and $24 \mathrm{~h}$. After taking pictures of the gaps, the size of the gap was measured for each sample. 
Table I Real-Time PCR Primers Sequence

\begin{tabular}{|l|l|l|}
\hline Gene Name & Forward Primer Sequence & Reverse Primer Sequence \\
\hline miR-I225-5p & GGTGGGTACGGCCCAGT & AGTGCAGGGTCCGAGGTATT \\
U6 & CTCGCTTCGGCAGCACA & AACGCTTCACGAATTTGCGT \\
YWHAZ & ATGACAAGAAAGGGATTG & AGAAGTTAAGGGCCAGAC \\
GAPDH & GGATTGTCTGGCAGTAGCC & ATTGTGAAAGGCAGGGAG \\
\hline
\end{tabular}

\section{Transwell Cell Invasion Assay}

In order to analyze the capability of the osteosarcoma cells to invade, transfected HOS or U2OS cells were plated in the upper chamber of the transwells (Corning) at a density of $6 \times 10^{4} /$ well in $300 \mu \mathrm{L} 1 \%$ FBS medium, and the upper chamber inserted into the lower chamber containing $700 \mu \mathrm{L}$ growth medium. The cells were cultured at $37^{\circ} \mathrm{C}, 5 \% \mathrm{CO}_{2}$ for $24 \mathrm{~h}$. The low FBS medium was removed from the upper chamber. The cells in the lower chamber were washed with PBS and fixed with $4 \%$ formalin at room temperature for 10 min. The cells were then stained with $0.5 \%$ Crystal Violet at room temperature for $30 \mathrm{~min}$ and washed with PBS 3 times. The number of cells that had migrated into the lower chamber was scored by taking a picture of the stained cells under microscope and the number of cells counted in each picture.

\section{Dual Luciferase Assay}

The whole 3' UTR sequence of YWHAZ gene (NCBI accession number: NM_001135699, DNA sequence is shown in the supplemental data) was synthesized and cloned into pGL3-promoter-Luc2 vector (Promega) to obtain pGL3-wt. A mutant 3' UTR sequence (DNA sequence is shown in the supplemental data) was created to eliminate the putative miR-1225-5P binding site and cloned into pGL3-PromoterLuc2 vector to obtain pGL3-mut. HOS osteosarcoma cells were plated in 6 -well plates and cultured at $37^{\circ} \mathrm{C}, 5 \% \mathrm{CO}_{2}$ for $16 \mathrm{~h}$. The cells were then co-transfected with combinations of (a) $1.5 \mu \mathrm{g}$ of pGL3-wt, $20 \mathrm{ng}$ of pGLl-TK (Promega), and $100 \mathrm{pmol}$ of scramble miRNA; (b) $1.5 \mu \mathrm{g}$ of pGL3-wt, $20 \mathrm{ng}$ of pGLl-TK, and $100 \mathrm{pmol}$ of miR-1225; (c) $1.5 \mu \mathrm{g}$ of pGL3mut, $20 \mathrm{ng}$ of pGLl-TK, and $100 \mathrm{pmol}$ of miR-1225, using Lipofectamine 2000 and following the kit protocol. The cells were washed with PBS and lysed with lysis buffer $48 \mathrm{~h}$ after transfection. Luciferase activity was analyzed with dual luciferase assay kit (Promega).

\section{Western Blot Analysis}

The cells on the plate were washed with ice cold PBS twice and lysed with radioimmunoprecipitation assay buffer (RIPA buffer). Tumor tissues were washed with ice cold PBS and $20 \mathrm{mg}$ of each sample were homogenized with a homogenizer on ice. After centrifugation at $12,000 \mathrm{rpm}, 4^{\circ} \mathrm{C}$ to remove the debris, protein concentration was measured with Pierce BCA Protein Assay Reagent A (Thermo Fisher Scientific US, Cat\# 23223). Approximately $25 \mu \mathrm{g}$ (from cells) or $50 \mu \mathrm{g}$ (from tissue) of protein was loaded into each well and separated by sodium dodecyl sulphate-polyacrylamide gel electrophoresis in a $10 \%$ polyacrylamide gel and transferred to immunoblot nitrocellulose (NC) membranes (Millipore). The membranes were incubated with primary antibody against YWHAZ (Abcam, Cat\# ab51129, 1:500 dilution) or GAPDH (Cell Signaling Technology, Cat\# 5174, 1:1000 dilution), followed by incubation with horseradish peroxidase conjugated secondary antibody. ECL Western blot analysis was used to detect the binding of primary and secondary antibodies in the Tanon 5200CE Chemi-image system (Abclonal, Woburn MA, USA).

\section{In vivo Tumor Model}

All in vivo tumor model studies were approved by the Jilin University Institutional Animal Care and Use Committee, and followed the guidelines adapted from the "Animal Welfare Act" (the federal law governing the care and use of laboratory animals in the United States). HOS osteosarcoma cells were cultured in $100 \mathrm{~mm}$ tissue culture dishes until about $90 \%$ confluent and then were harvested from culture dishes with $0.05 \%$ Trypsin (Life Technology). The cells were re-suspended in PBS at a final concentration of $2 \times 10^{7}$ cells/mL. Six-week-old female Balb/c athymic nude mice were obtained from Shanghai Experimental Animal Center of Chinese Academy of Sciences and were bred in a special pathogen-free (SPF) grade laboratory. The mice were randomly divided into 2 groups with 6 mice in each group. Each mouse received $100 \mu \mathrm{L}$ of cells $\left(2 \times 10^{6}\right.$ cells $)$ injected subcutaneously. The mice were monitored closely every day. The tumor sizes were measured when they started to be visible and every 3 days thereafter. The volume of the tumor was calculated by using the formula: 
$\mathrm{V}=(4 / 3) \times \pi \times(\mathrm{L} / 2) \times(\mathrm{L} / 2) \times(\mathrm{D} / 2)(\mathrm{L}$ means length and $\mathrm{D}$ means depth). Lung metastasis was examined by dissecting the whole lungs. Quantification of the metastasis was conducted by counting the number of tumors on the lung surface. After counting the metastasis tumor numbers in the lungs, the lungs were fixed in $10 \%$ formalin and embedded in paraffin for tumor histology.

\section{Cell Cycle Profile Analysis}

Transfected HOS or U2OS cells were trypsinized from culture dishes and washed with ice cold PBS twice. After removing $\mathrm{PBS}$, the cells were fixed with ice cold $70 \%$ ethanol at $4^{\circ} \mathrm{C}$ for $24 \mathrm{~h}$. The cells were then washed with PBS and stained with $20 \mu \mathrm{g} / \mathrm{mL}$ propidium iodide (Cell Cycle and Apoptosis Analysis kit, Beyotime) in $0.1 \%$ Triton-X 100/PBS with $0.2 \mathrm{mg} / \mathrm{mL}$ RNase A at a final concentration of $2 \times 10^{6}$ cells $/ \mathrm{mL}$ at $37^{\circ} \mathrm{C}$ for $30 \mathrm{~min}$. After staining, the cells were kept on ice and subject to FACS analysis (Beckman CytoFLEX flow cytometer). The cell cycle profile data were analysed using FlowJo software.

\section{Results}

\section{miR-I 225-5P Targeted 3' UTR of YWHAz Gene and Inhibited YWHAZ}

\section{Expression in Osteosarcoma Cells}

In multiple osteosarcoma cell lines, miR-1225-5P expression was detected by real-time PCR (Figure 1A). The level of expression varies from cell line to cell line. Interestingly, the expression of Ywhaz gene on the mRNA level in the same set of cell lines was roughly conversely correlated to the expression of miR-1225-5P. For instance, among the 5 cell lines tested, the cell lines that express the highest and the lowest miR-1225-5P are HOS and hFOB1.19, respectively (Figure 1A), and the expression of Ywhaz in HOS and hFOB1.19 cell lines were the lowest and the highest, respectively (Figure 1B). Western blot confirmed the finding of reverse-correlation of miR-1225-5P and YWHAZ expression on the protein level (Figure 1C). This finding indicates that miR-1225-5P can potentially be a novel negative regulator of YWHAZ expression. To confirm this hypothesis, we performed a database search (www.mirbase.org) and found that miR-1225-5P potentially targets $3^{\prime}$ UTR of human Ywhaz gene by alignment of sequences (Figure 1D). This was further validated by transfecting miR-1225-5P mimic into HOS osteosarcoma cells: increasing miR-1225-5P significantly inhibited Ywhaz expression (Figure 1E). Inhibiting miR-1225-5P significantly increased Ywhaz expression in U2OS osteosarcoma cells
(Figure 1E). To further confirm that miR-1225-5P targets Ywhaz gene 3' UTR sequence, we constructed luciferase reporter plasmid by cloning $3^{\prime}$ UTR of Ywhaz gene to $3^{\prime}$ of luciferase reporter gene. The luciferase reporter assay showed that miR-1225-5P downregulated luciferase activity by targeting Ywhaz gene 3' UTR (Figure 1F). Luciferase activity was not reduced when the miR-1225-5P targeting sequence was mutated (Figure 1F). These data indicate that miR-1225-5P is a novel negative regulator of Ywhaz expression.

\section{MiR-I 225-5P Inhibited Osteosarcoma Cells' Growth and Migration in vitro}

Targeting Ywhaz expression has been shown to inhibit other cancer cells' proliferation and migration. ${ }^{20-22}$ Here we asked the question of whether miR-1225 inhibits osteosarcoma cells' growth and migration by negatively regulating Ywhaz expression. As observed above, HOS osteosarcoma cells transfected with miR-1225 mimic significantly reduced expression of Ywhaz (Figure 1E). HOS osteosarcoma cells transfected with miR-1225 5P mimic showed significantly slower growth compared with the cells transfected with scramble miRNA (Figure 2A). Wound healing assay further showed that the miR-1225-5P mimic transfected cells migrate significantly slower than control cells transfected with scramble miRNA (Figure $2 \mathrm{~B}$ and $\mathrm{C}$ ). In order to address the question of whether miR-1225-5P inhibits osteosarcoma cells invasion, we used a transwell cell invasion assay. HOS osteosarcoma cells transfected with miR-1225-5P or scramble miRNA control were plated in the upper chamber of the transwell. After being cultured for $24 \mathrm{~h}$, the cells that migrated through the transwell into the lower chamber of the plate were fixed, stained and the cell number was counted after imaging. As shown in Figure 2D and E, miR-1225-5P significantly inhibited osteosarcoma cells invasion. The cell number collected in the lower chamber from miR-1225-5P transfected cells was $18 \pm 4$, which is about a $86 \%$ reduction compared with the control scramble miRNA transfection cells (116 \pm 6$)$. These data indicate that miR-1225-5P inhibited osteosarcoma cells' growth, migration, and invasion by downregulating Ywhaz expression.

\section{Inhibiting miR-I225-5P Promoted Osteosarcoma Cells Growth and Migration}

Since increasing miR-1225-5P in osteosarcoma cells inhibited cell growth and migration, we further asked whether inhibiting miR-1225-5P will promote osteosarcoma cells' 
miR-1225

A

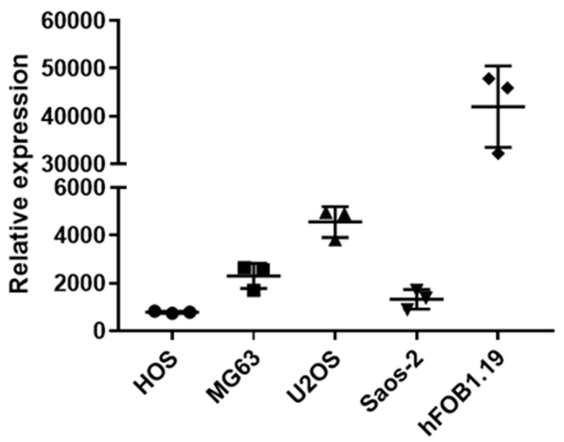

C

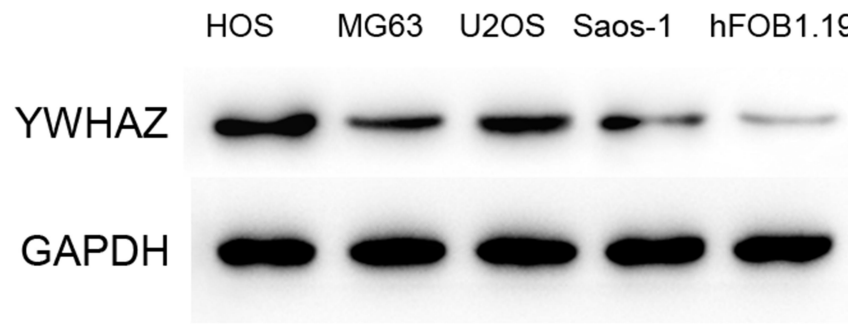

E

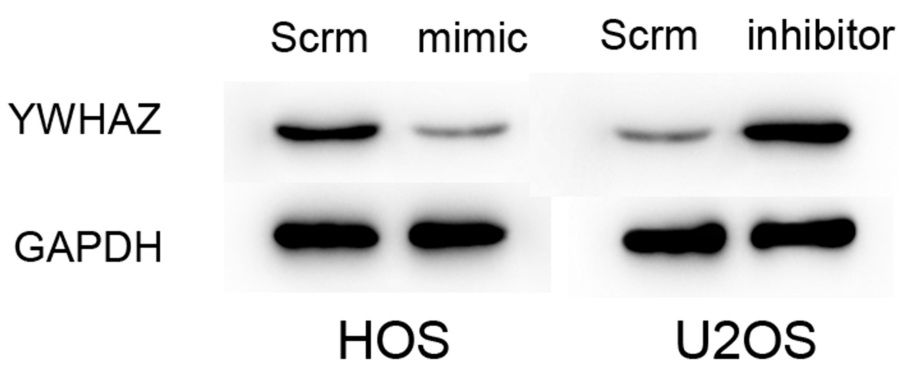

B

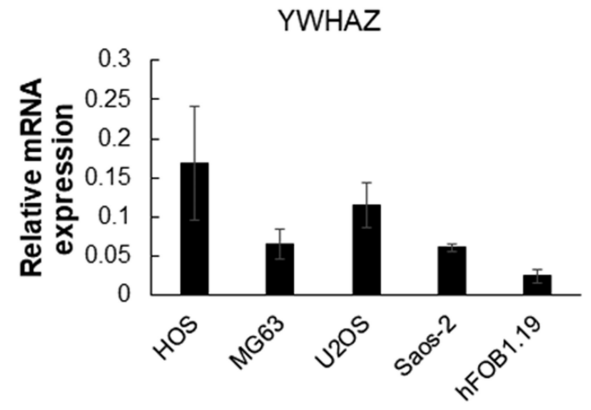

D

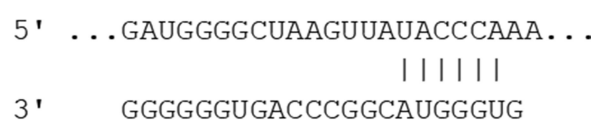

F

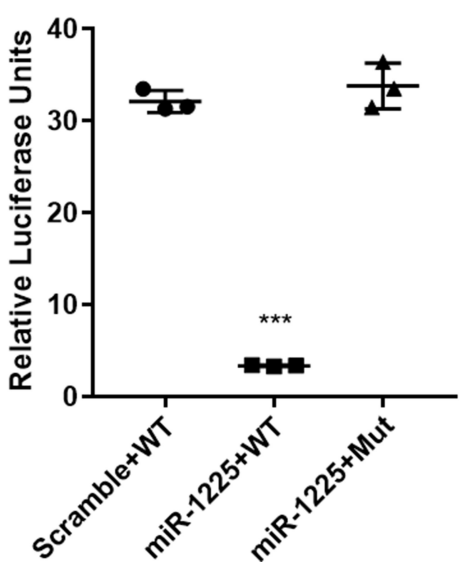

Figure I Hsa-miR-1225-5P targeted YWHAZ 3'UTR and negatively regulated YWHAZ expression in osteosarcoma cells. (A) Hsa-miR-I225-5P was expressed in different human osteosarcoma cell lines. (B) Relative mRNA expression of YWHAZ in human osteosarcoma cells lines showed a rough reverse correlation to the expression of miR1225-5P in each cell line. (C) Western blot showed YWHAZ protein expression in human osteosarcoma cell lines, which confirmed the reverse correlation to the expression of miR-1225-5P in the cell lines. (D) Sequence alignment of miR-1225-5P and 3' UTR of YWHAZ gene showed that YWHAZ is a potential target of miR-I225-5P. (E) Transfection of miR-1225-5P mimic or inhibitor, increased or decreased YWHAZ expression on the protein level in HOS or U2OS cells. (F) Luciferase assay confirmed that miR-I 225-5P targets YWHAZ 3' UTR and regulates YWHAZ expression. ***indicates $\mathrm{P}<0.00 \mathrm{I}$ compared with no transfection or scramble control.

growth and migration. Inhibiting miR-1225-5P significantly increased YWHAZ expression on the protein level in U2OS osteosarcoma cells (Figure 1E). To address this question, we transfected miR-1225-5P inhibitor into U2OS osteosarcoma cells with scramble inhibitor as a control. The U2OS cells transfected with miR-1225-5P grew significantly faster compared with the cells transfected with scramble (Figure 3A). Inhibiting miR-1225-5P increased U2OS cells' wound healing capacity (Figure 3B and C). Inhibiting miR-1225-5P also promoted U2OS cell migration through transwells (Figure 3D and E). These data further proved that miR-
1225-5P regulates osteosarcoma cells proliferation, migration, and invasion by targeting YWHAZ expression.

\section{miR-I 225-5P Regulated Osteosarcoma Cells Proliferation by Affecting GI/G0 Phase Exit}

We further asked, what is the mechanism of miR-1225-5P in regulating osteosarcoma cell proliferation through YWHAZ? After HOS or U2OS cells were transfected with miR-1225-5P mimic or inhibitor, the cells were fixed and analyzed with cell cycle profile by DNA 
A

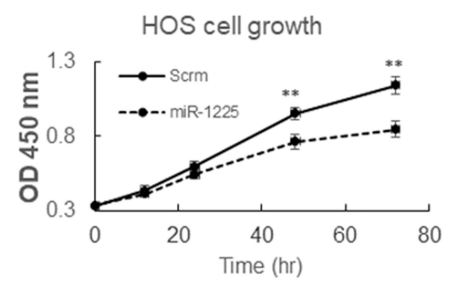

C

$0 \mathrm{hr}$

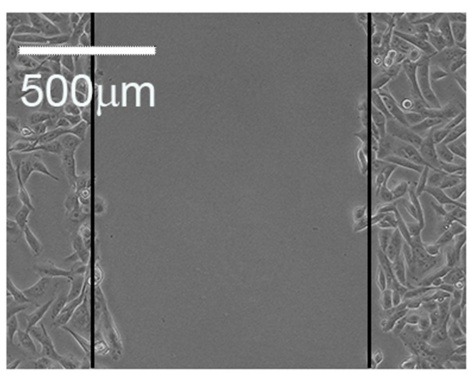

Scrm

D

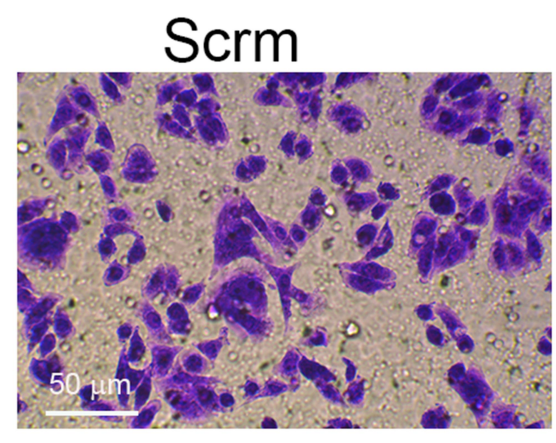

B

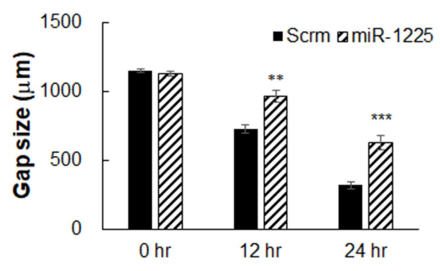

$12 \mathrm{hr}$

$24 \mathrm{hr}$
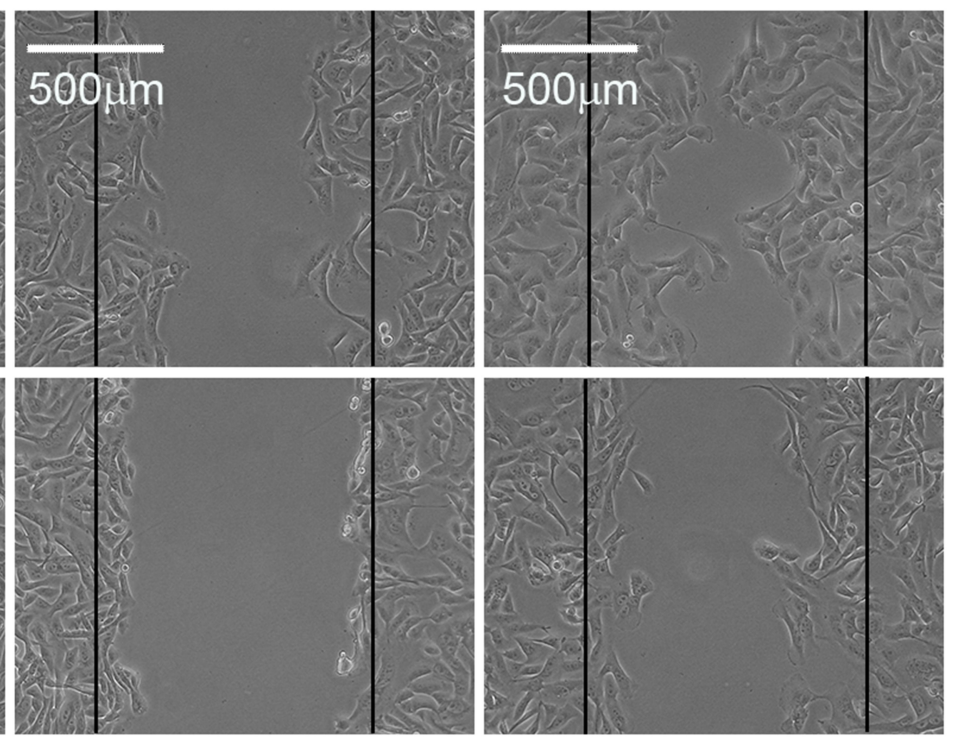

E

miR-1225

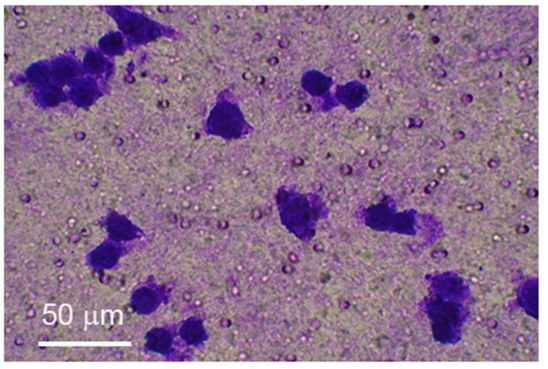

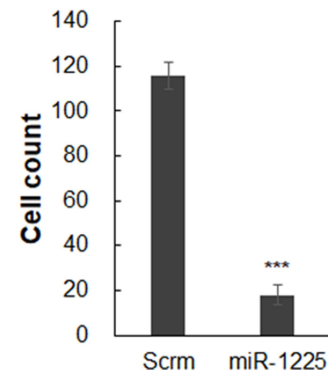

Figure 2 Hsa-miR-I225-5P inhibited HOS osteosarcoma cell growth, migration and invasion. (A) Transfection of Hsa-miR-I225-5P mimic in HOS cells inhibited HOS cell growth. (B) Quantification of the HOS cell wound gap after 12 and $24 \mathrm{~h}$ culture $(n=3)$, which showed transfection of miR-1225-5P mimic slowed HOS wound healing in cell culture dish. (C). Representative pictures of HOS osteosarcoma cells wound gap at 0, 12, and $24 \mathrm{~h}$ of culture. (D) Representative pictures of crystal violet stained HOS cells in the bottom chamber of transwells. (E) Quantification of HOS cells migrated through transwells to the bottom chamber $(\mathrm{n}=3$ ). $* *$ Indicates $\mathrm{P}<0.0 \mathrm{I}$ and $* * * i n d i c a t e s$ $\mathrm{P}<0.00$ I compared with scramble control.

contents. As shown in Figure 4A and B, HOS transfected with miR-1225-5P mimic significantly increased percentage of cells in $\mathrm{G} 1 / \mathrm{G} 0$ phase (68\%) compared with those transfected with scramble (52\%). However, inhibiting miR-1225-5P in U2OS cells significantly decreased the percentage of cells in $\mathrm{G1} / \mathrm{G} 0$ phase (35\%) compared with control (53\%) (Figure 4C and D). These data indicate that miR-1225-5P regulates osteosarcoma cell proliferation by affecting G1/G0 phase exit via regulating YWHAZ expression. 
Over-Expression of YWHAZ Attenuated the Inhibition Effect of miR-I225-5P in Osteosarcoma Cells' Proliferation, Migration and Cell Cycle Progression

To further elucidate that miR-1225-5P regulates osteosarcoma cell proliferation and migration by targeting YWHAZ, we used YWHAZ gain-of-function strategy. HOS osteosarcoma cells were transfected with pCDNA3.1 expression vector containing Ywhaz coding sequence (Ywhaz/pCDNA) combined with miR-1225-5P mimic or scramble. HOS cells transfected with pCDNA3.1 empty vector combined with miR-1225-5P mimic or scramble were used as controls. Therefore, 4 groups of cells (Vector + Scramble, Vector + mimic, $Y w h a z+$ Scramble, and Ywhaz + mimic) were analyzed for cell proliferation, migration, invasion, and cell cycle profile. Western blotting analysis confirmed overexpression of YWHAZ in YWHAZ + Scramble HOS cell group (Figure 5A). Western blotting analysis also confirmed downregulated YWHAZ expression in Vector + mimic HOS cell group (Figure 5A). In these 4 groups of HOS osteosarcoma cells, the expression level of YWHAZ correlated with the cell growth. Cells overexpressed with YWHAZ (YWHAZ + Scramble group) proliferated significantly faster than Vector + Scramble and Vector + mimic groups (Figure $5 \mathrm{~B}$ ). It was also further confirmed that knocking down YWHAZ in Vector + mimic group inhibited cell growth (Figure 5A and B). These data hinted that YWHAZ promotes osteosarcoma cell proliferation. In the wound healing assay, the gap sizes of YWHAZ + Scramble group were significantly smaller than Vector + Scramble and Vector + mimic groups (Figure 5C and D). In the transwell invasion assay, significantly higher numbers of cells were observed in the lower chamber in YWHAZ + Scramble group than in Vector + Scramble group (Figure 5E). Knocking down of YWHAZ in Vector + mimic group significantly inhibited cell invasion which confirmed our observation in Figure 2D. In the cell cycle profile analysis, YWHAZ + Scramble group cells had a significantly lower percentage of $\mathrm{G} 1 / \mathrm{G} 0$ phase cells $(30.16 \pm 1.54 \%)$ compared with the other 3 groups of cells and Vector + mimic group cells increased percentage of G1/G0 arrested cells $(68.23 \pm 1.41 \%)$ compared with that of control Vector + Scramble group cells $(50.88 \pm 2.49 \%$ ) (Figure $5 \mathrm{~F}$ and $\mathrm{G}$ ). Of note, cotransfection of YWHAZ and miR-1225-5P mimic significantly reduced the effects of YWHAZ overexpression. These data indicated that miR-1225-5P negatively regulates osteosarcoma cells proliferation, migration, invasion, and cell cycle progression by (at least in part) targeting YWHAZ.

\section{miR-I225-5P Inhibited Osteosarcoma Tumor Growth and Metastasis in vivo}

Our finding that miR-1225-5P inhibited osteosarcoma cells' proliferation, migration, and invasion by targeting YWHAZ expression and induced G1/G0 cell cycle arrest in vitro, leads us to further hypothesize that miR-1225-5P inhibits osteosarcoma tumor growth in vivo. To test this hypothesis, we established an in vivo tumor model by injecting HOS osteosarcoma cells subcutaneously in nude mice. The mice were intravenously injected with miR1225-5P mimic or scramble miRNA daily for 3 weeks. The tumor sizes were measured every 3 days. The mice injected with miR-1225-5P mimic showed significantly slower tumor growth compared with those injected with scramble miRNA (Figure 6A). Thirty-three days after the osteosarcoma cell inoculation, the mice were sacrificed and the tumors were dissected. H\&E staining confirmed that the dissected tumor tissues were osteosarcoma (data not shown). As shown in Figure 6B, the tumors from mice injected with miR-1225-5P mimic were significantly smaller compared with those injected with scramble miRNA (Figure 6B). Real-time PCR analysis and Western blot revealed that the expression of YWHAZ on both mRNA and protein levels were significantly lower in the tumors that received miR-1225-5P mimic IV injection compared with those that received scramble miRNA injection (Figure 6C and D), indicating that miR-1225-5P injection reduced YWHAZ expression in vivo. Lung metastasis of osteosarcoma was assayed by dissecting whole lungs and counting tumor numbers from the lungs of each mouse. After counting the lung metastasis, the lungs were fixed in formalin and embedded in paraffin. Paraffin sections and H\&E staining of the lungs confirmed metastatic tumors in lungs (supplemental Figure S1). The mice injected with miR-1225-5P mimic showed a significantly lower number of tumors in the lungs compared with those injected with scramble miRNA (Figure 6E). These data indicate that miR-1225-5P not only inhibited tumor growth in vivo, but also inhibited metastasis by downregulating expression of YWHAZ in osteosarcoma. 
A
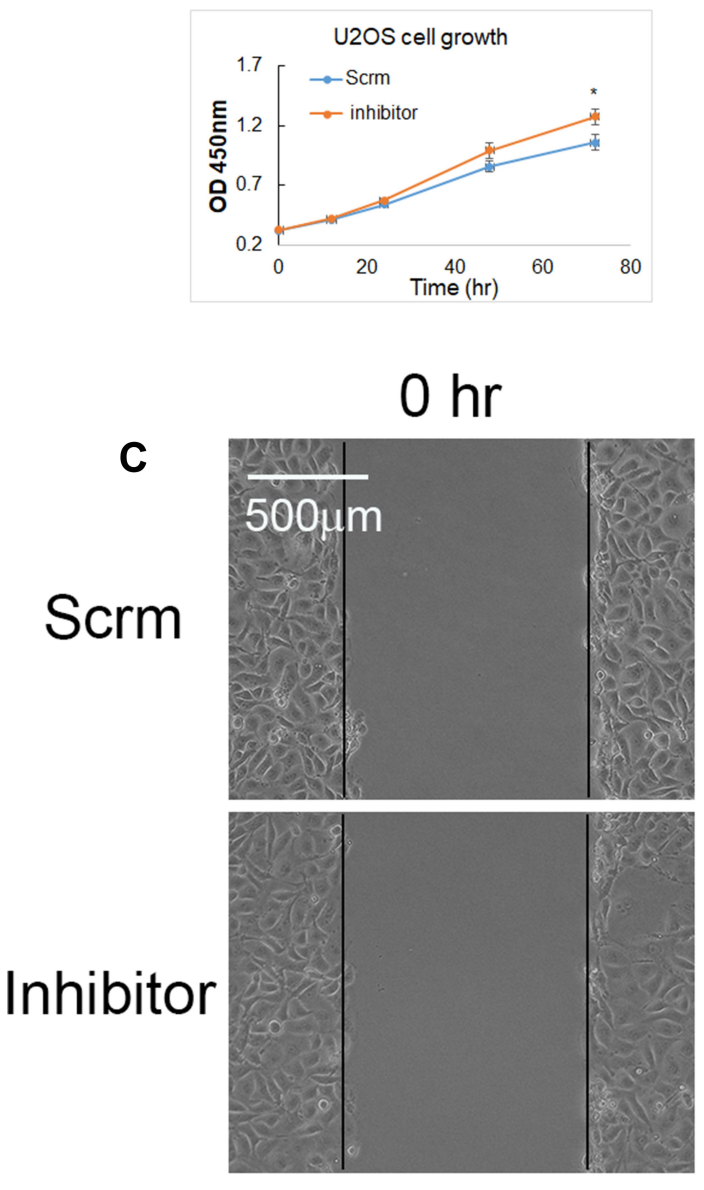

D

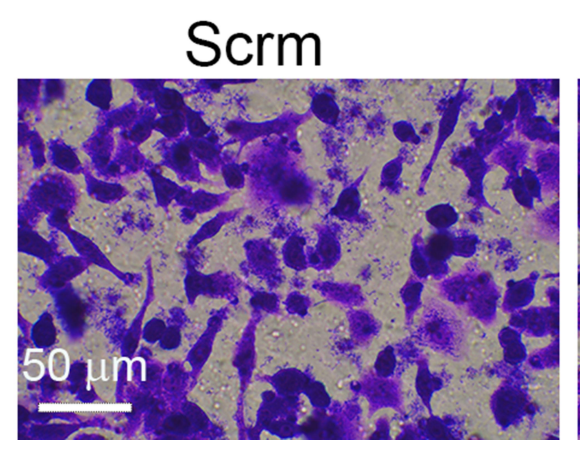

B
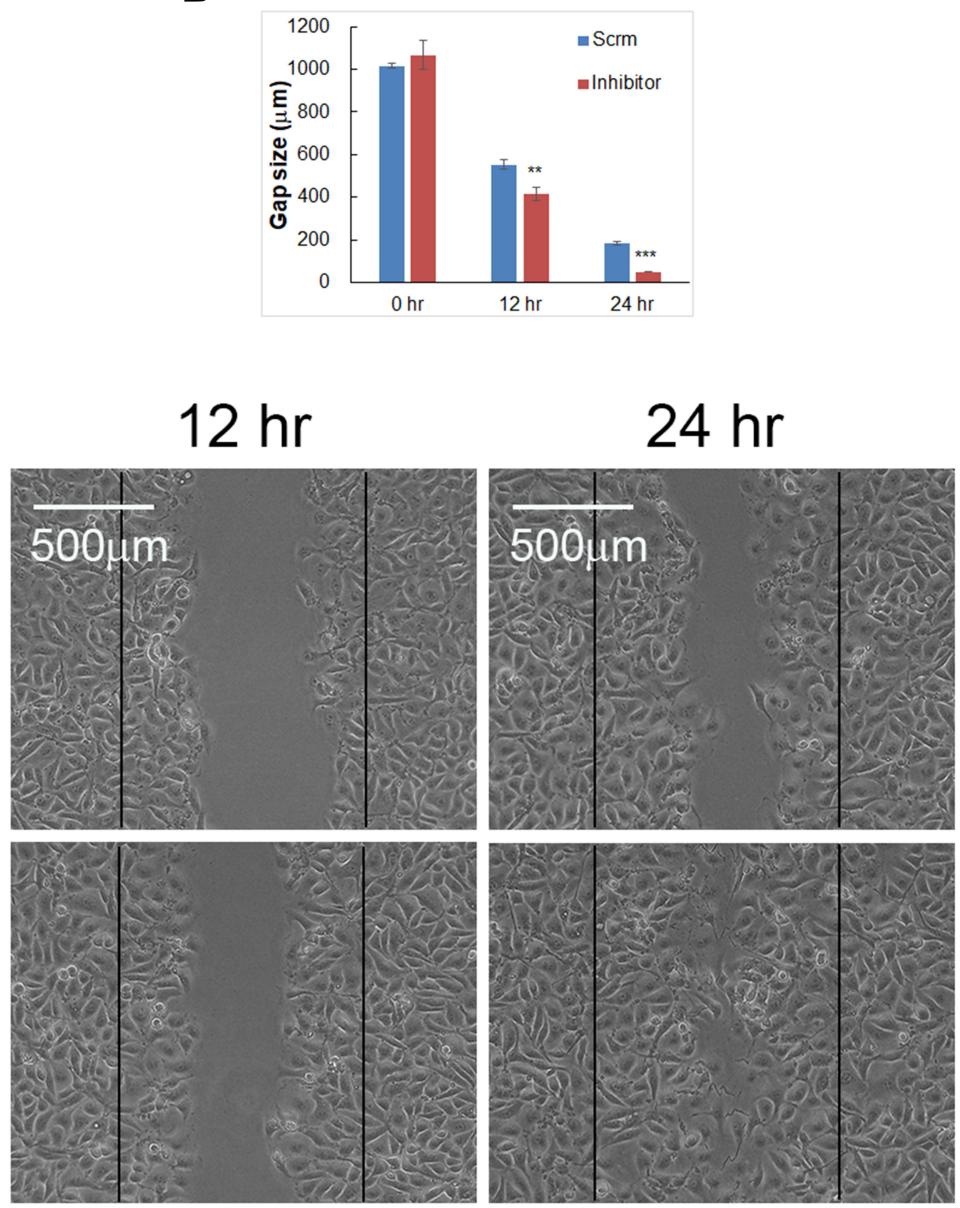

E
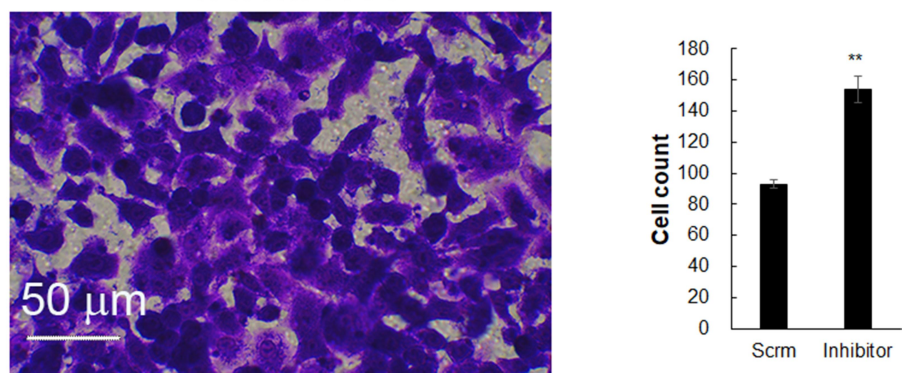

Figure 3 Inhibiting miR-1225-5P increased U2OS osteosarcoma cell growth, migration, and invasion. (A) Transfection of miR-1225-5P inhibitor increased U2OS cell growth. (B) Quantification of U2OS cells wound gap after 12 and $24 \mathrm{~h}(\mathrm{n}=3)$, which showed that miR-1225-5P inhibitor significantly increased wound healing in cell culture dishes. (C) Representative pictures of U2OS cells wound gap at 0,12 , and $24 \mathrm{~h}$ of culture. (D) Representative pictures of crystal violet stained U2OS cells that invaded through transwells to the bottom chamber of the wells. (E) Quantification of U2OS cells in the bottom chambers $(\mathrm{n}=3$ ). *Indicates $\mathrm{P}<0.05$, $* *$ indicates $\mathrm{P}<0.0 \mathrm{I}$ and $* * * i n d i c a t e s$ $\mathrm{P}<0.001$ compared with scramble control.

\section{Discussion}

Osteosarcoma is the most common primary malignant of the bone. Patients with metastasis or relapse experience poor prognosis and low overall survival rate. ${ }^{2,23}$ The mechanisms of osteosarcoma malignancy and metastasis are not fully understood. Abnormal miRNA expression may be a possible part of malignant transformation mechanisms of osteosarcoma. ${ }^{17,24}$ Using data mining, Zhang et al. found that aberrant expression of miR-1225-5P in osteosarcoma and low expression was associated with poor prognosis. ${ }^{25}$ In the present study, we found that the higher expression of YWHAZ was reversely correlated with the expression of miR-1225-5P. We further 
A

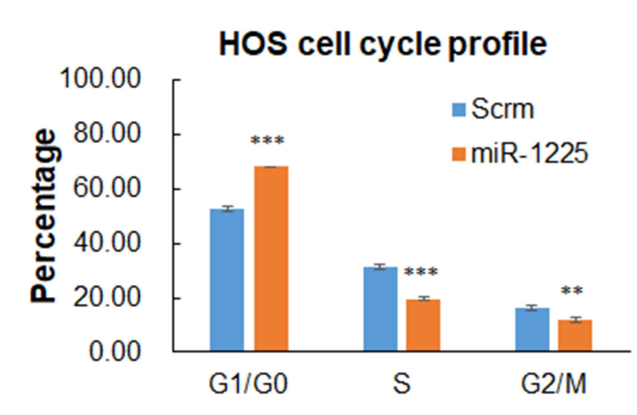

B

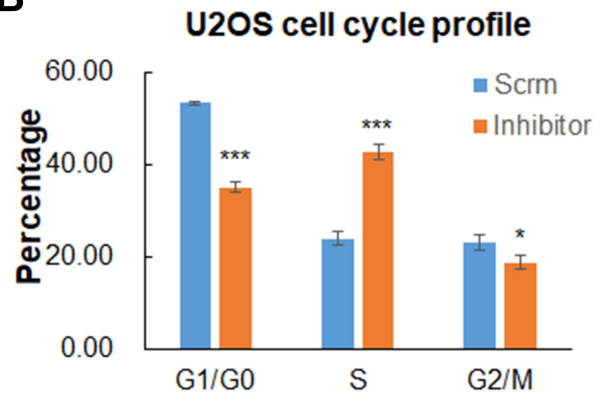

Scrm

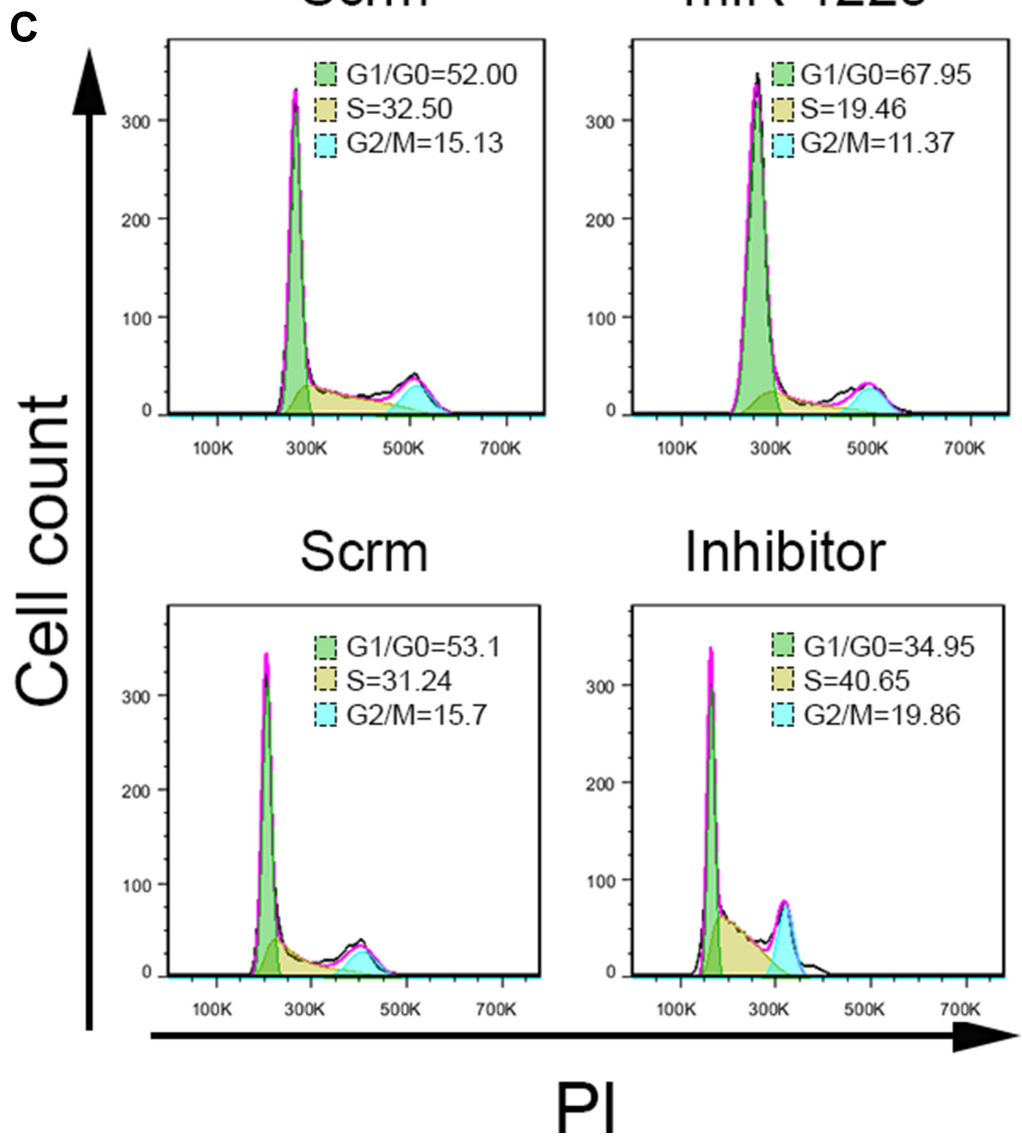

Figure 4 Hsa-miR-I225-5P inhibited osteosarcoma cells' cell cycle exiting from GI/G0 to S phase. (A) Transfection of miR-I225-5P mimic in HOS osteosarcoma cells, increased GI/G0 phase cells from 52\% to 68\%. (B) Transfection of miR-I225-5P inhibitor in U2OS cells decreased GI/G0 phase cells from 53\% to $35 \%$. (C) Representative FACS plot showed the increasing and decreasing percentage of GI/G0 phase cells after transfection with miR-1225-5P mimic or inhibitor respectively compared with that of scramble controls. *Indicates $\mathrm{P}<0.05$, **indicates $\mathrm{P}<0.01$ and $* * *$ indicates $\mathrm{P}<0.00 \mathrm{I}$ compared with scramble control.

discovered that miR-1225-5P regulates YWHAZ expression by targeting YWHAZ 3' UTR. In vitro evidence demonstrated that miR-1225-5P negatively regulates osteosarcoma cells' growth, migration and invasion via negatively regulating YWHAZ expression in osteosarcoma cell lines.

Accumulating evidence shows that YWHAZ serves a role in many types of cancers ${ }^{3,4,6-8,10}$ and promotes cancer metastasis. $^{26-28}$ Targeting YWHAZ has been suggested as an option for cancer treatment. ${ }^{9}$ YWHAZ was reported to be involved in cancer cell cycle regulation, especially in G1/G0 phase to S phase transition. ${ }^{29-31}$ Our in vitro evidence showed that inhibiting YWHAZ expression by overexpression of miR-1225-5P increased osteosarcoma cell G1/G0 arrest, inversely, over-expression of YWHAZ reduced G1/G0 cell percentage in osteosarcoma cell line. These data suggest that YWHAZ plays a critical role in osteosarcoma cells' cell cycle regulation, namely G1/G0 phase to $S$ phase transition.

MiR-1225-5P has been reported as a tumor suppressor in thyroid cancer, ${ }^{32}$ pancreatic cancer, ${ }^{33}$ glioblastoma, $^{34}$ laryngeal cancer, ${ }^{35}$ and gastric carcinoma $^{36}$ and osteosarcoma ${ }^{25}$ by targeting different genes and through different pathways. Zhang and colleagues' in vitro work $^{25}$ revealed that miR-1225-5P inhibits SOX9 expression in the osteosarcoma cell line and acts as a suppressor. In the present study, we found that miR-1225-5P negatively regulates YWHAZ posttranscriptional expression by targeting its $3^{\prime}$ UTR. Through inhibiting YWHAZ expression, miR-1225-5P inhibits osteosarcoma cells' growth, migration and invasion. Our in vivo work further revealed that intravenous injection of miR-1225-5P inhibited tumor growth and 


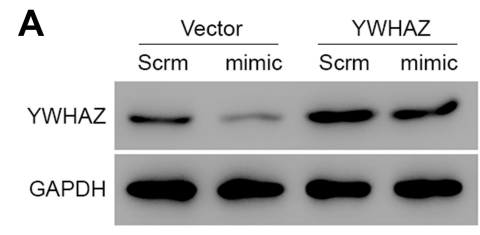

D
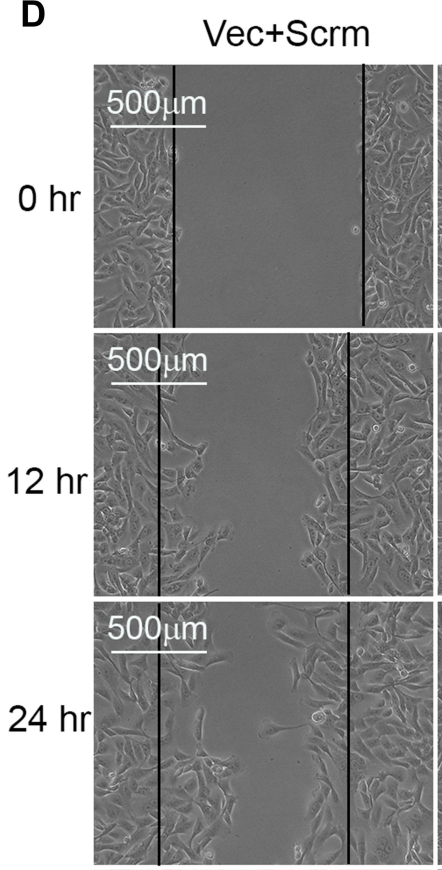

E

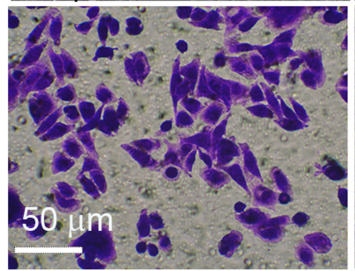

B

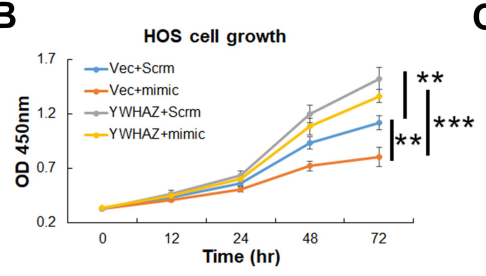

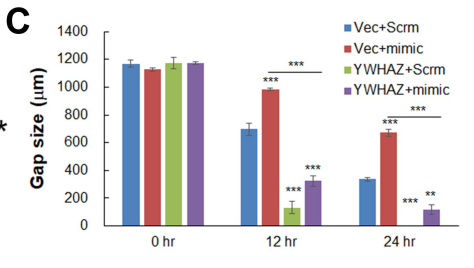

YWHAZ+Scrm

YWHAZ+mimic
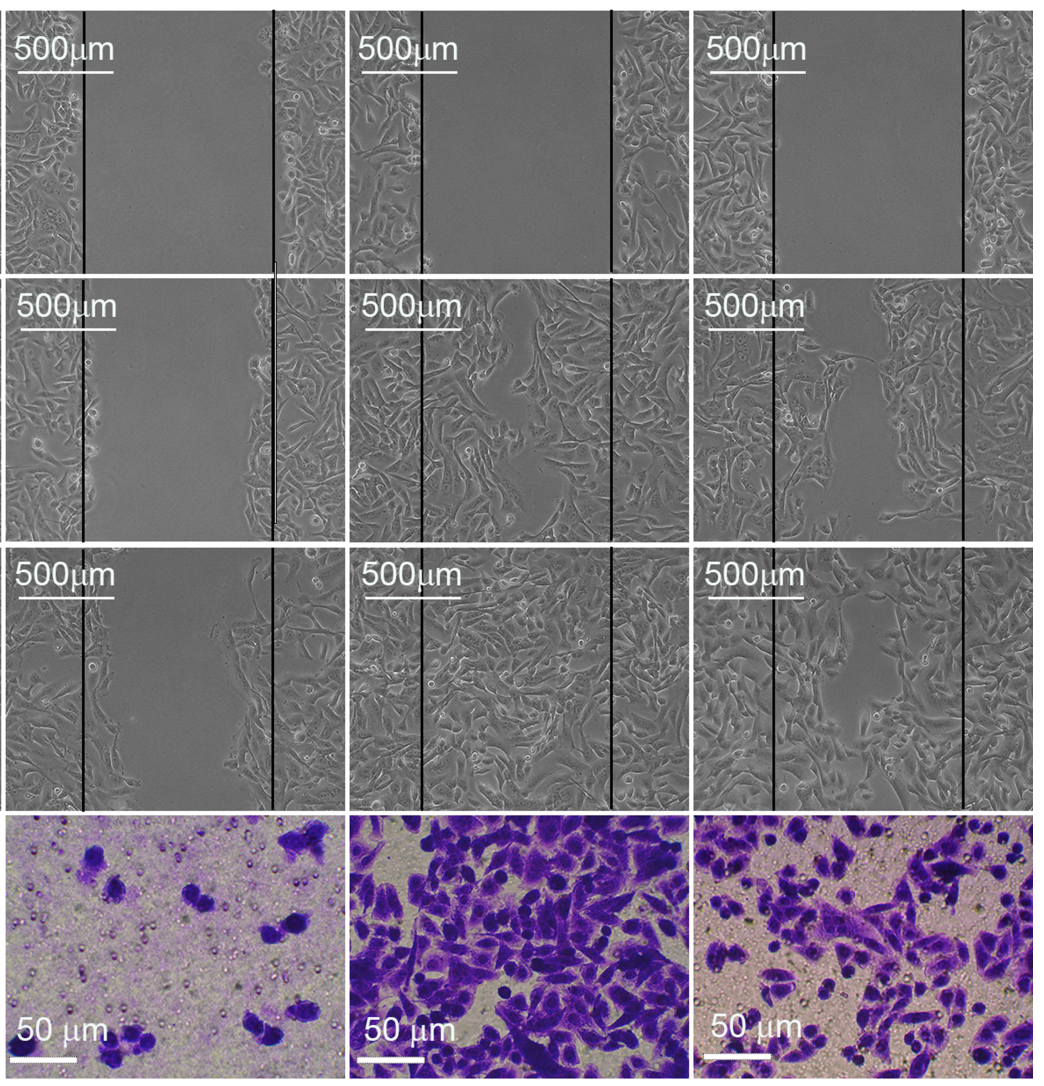

F
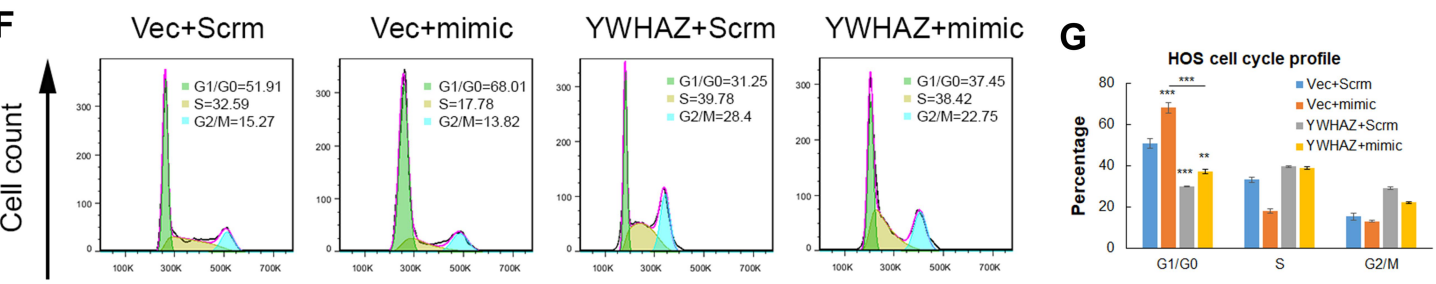

PI

Figure 5 Overexpression of YWHAZ rescued inhibition of osteosarcoma cell growth, migration, and invasion caused by miR-1225-5P. (A) Western blot showed that overexpression of YWHAZ partially restored YWHAZ protein level in HOS osteosarcoma cells (lane 4). YWHAZ expression was knocked down by miR-1225-5P mimic (lane 2). (B) Over-expression of YWHAZ increased HOS cells growth (blue line and grey line, $P<0.01 \mathrm{n}=3$ ), and rescued the inhibition of HOS cell growth (yellow line and red line, $P<0.001 \mathrm{n}=3$ ) caused by miR-1225-5P mimic. (C) Quantification of HOS cells wound gap after 12 and $24 \mathrm{~h}$ culture. (D) Representative pictures of HOS cells wound gap after 12 and $24 \mathrm{~h}$ culture showed that over-expression of YWHAZ accelerated wound healing in the cell culture dishes. (E) Transwell invasion assay showed that inhibition of YWHAZ expression by miR-1225-5P mimic decreased HOS cells invasion and over-expression of YWHAZ increased HOS cells invasion. (F) Representative FACS histogram plots showed that YWHAZ over-expression decreased GI/G0 phase arrest induced by miR-1225-5P. (G) Average percentage of each phase in cell cycle $(n=3$ each group) showed that YWHAZ over-expression decreased GI/G0 phase arrest induced by miR-1225-5P. **Indicates $P<0.01$ in the indicated comparison, ***indicates $\mathrm{P}<0.001$ in the indicated comparison. 
A

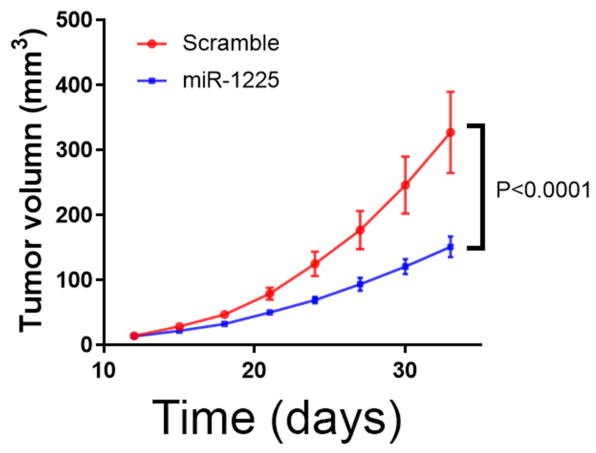

C

YWHAZ

GAPDH
B

\section{Scrm}

mimic

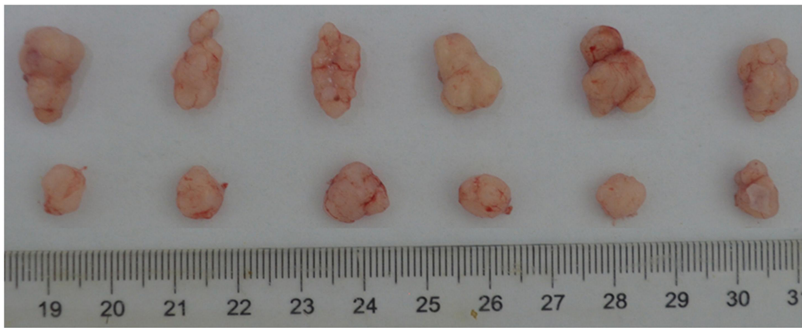

mimic

D

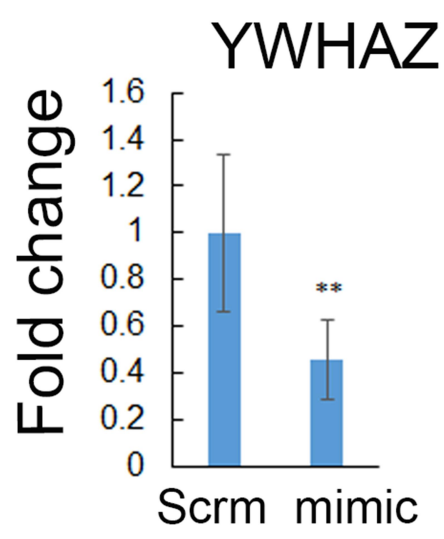

E Lung metastasis

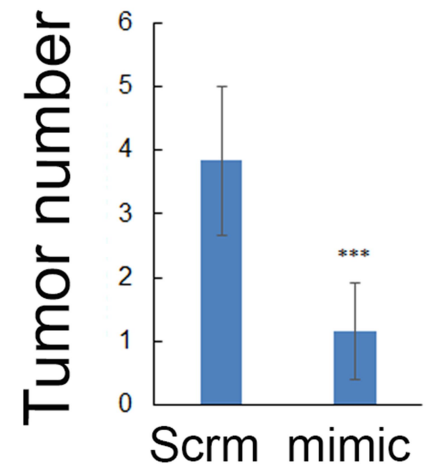

Figure 6 Hsa-miR-1225-5P inhibited osteosarcoma tumor growth and lung metastasis in vivo. (A) Tumor growth curves in nude mice indicated that miR-1225-5P inhibited tumor growth (blue line) compared with scramble miRNA treatment (red line) $(n=6, P<0.0001)$. (B) Picture of tumors at the end time point showed smaller sizes of miRI225-5P treated tumors compared with scramble miRNA treated. (C) Western blot showed lower expression of YWHAZ in the tumor tissue treated with miR-1225-5P mimic compared with scramble miRNA treated. (D) Real-Time PCR showed YWHAZ expression on mRNA level was lower in miR-I225-5P treated tumors compared with scramble-treated tumors $(n=6)$. (E) Quantification of lung metastasis from surface of each lung $(n=6, P<0.00 I)$. $* *$ indicates $P<0.0 \mathrm{I}$ and $* * *$ Indicates $\mathrm{P}<0.00 \mathrm{I}$ compared with scramble control.

lung metastasis by downregulating YWHAZ. To our knowledge, this is the first report that demonstrates miR-1225-5P inhibits osteosarcoma growth and metastasis in a mouse model.

Taken together, our present study revealed that miR1225-5P negatively regulates YWHAZ expression in osteosarcoma cells, and inhibits osteosarcoma cells' growth, migration and invasion in vitro. Moreover, our in vivo mouse model further proved that miR-1225-5P inhibits tumor growth and metastasis. This study provided evidence that miR-1225-5P could potentially be used as an osteosarcoma treatment therapy.

\section{Patient Consent for Publication}

No patients are involved.

\section{Ethics Approval and Consent to Participate}

This study does not contain any studies with human participants performed by any of the authors. 
All in vivo tumor mouse model studies were approved by the Jilin University Institutional Animal Care and Use Committee, and followed the guidelines adapted from the "Animal Welfare Act" (the federal law governing the care and use of laboratory animals in the United States).

\section{Author Contributions}

All authors made substantial contributions to conception and design, acquisition of data, or analysis and interpretation of data; took part in drafting the article or revising it critically for important intellectual content; agreed to submit to the current journal; gave final approval of the version to be published; and agree to be accountable for all aspects of the work.

\section{Disclosure}

The authors have no competing interests.

\section{References}

1. Ottaviani G. The epidemiology of osteosarcoma. Cancer Treat Res. 2009;152::3-13.

2. Duchman KR, Gao Y. Prognostic factors for survival in patients with high-grade osteosarcoma using the Surveillance, Epidemiology, and End Results (SEER) Program database. Cancer Epidemiol. 2015;39 (4):593-599. doi:10.1016/j.canep.2015.05.001

3. Murata T, Takayama K, Urano T, et al. 14-3-3zeta, a novel androgen-responsive gene, is upregulated in prostate cancer and promotes prostate cancer cell proliferation and survival. Clin Cancer Res. 2012;18 (20):5617-5627. doi:10.1158/1078-0432.CCR-12-0281

4. Li Y, Zou L, Li Q, et al. Amplification of LAPTM4B and YWHAZ contributes to chemotherapy resistance and recurrence of breast cancer. Nat Med. 2010;16(2):214-218. doi:10.1038/nm.2090

5. Bergamaschi A, Christensen BL. Reversal of endocrine resistance in breast cancer: interrelationships among 14-3-3zeta, FOXM1, and a gene signature associated with mitosis. Breast Cancer Res. 2011;13(3):R70. doi:10.1186/bcr2913

6. Lin M, Morrison CD, Jones S, Mohamed N, Bacher J. Copy number gain and oncogenic activity of YWHAZ/14-3-3zeta in head and neck squamous cell carcinoma. Int $J$ Cancer. 2009;125(3):603-611. doi:10.1002/ijc. 24346

7. Jiang H, Xia J, Kang J, Ding Y. Short hairpin RNA targeting beta-catenin suppresses cell proliferation and induces apoptosis in human gastric carcinoma cells. Scand J Gastroenterol. 2009;44 (12):1452-1462. doi:10.3109/00365520903342166

8. Chen CH, Chuang SM, Yang MF, Liao JW, Yu SL. A novel function of YWHAZ/beta-catenin axis in promoting epithelial-mesenchymal transition and lung cancer metastasis. Mol Cancer Res. 2012;10 (10):1319-1331. doi:10.1158/1541-7786.MCR-12-0189

9. Gan Y, Ye F. The role of YWHAZ in cancer: A maze of opportunities and challenges. $J$ Cancer. 2020;11(8):2252-2264. doi:10.7150/ jca.41316

10. Nishimura Y, Komatsu S, Ichikawa D, et al. Overexpression of YWHAZ relates to tumor cell proliferation and malignant outcome of gastric carcinoma. Br J Cancer. 2013;108(6):1324-1331. doi:10.1038/bjc.2013.65

11. Neal CL, Yao J, Yang W, et al. 14-3-3zeta overexpression defines high risk for breast cancer recurrence and promotes cancer cell survival. Cancer Res. 2009;69(8):3425-3432. doi:10.1158/0008-5472.CAN-082765
12. Kim HJ, Sung SH, Kim CY, et al. 14-3-3zeta overexpression is associated with poor prognosis in ovarian cancer. Yonsei Med J. 2018;59(1):51-56. doi:10.3349/ymj.2018.59.1.51

13. Danes CG, Wyszomierski SL, Lu J, Neal CL, Yang W. 14-3-3 zeta down-regulates p53 in mammary epithelial cells and confers luminal filling. Cancer Res. 2008;68(6):1760-1767. doi:10.1158/0008-5472. CAN-07-3177

14. Neal CL, Xu J, Li P, et al. Overexpression of 14-3-3zeta in cancer cells activates PI3K via binding the p85 regulatory subunit. Oncogene. 2012;31(7):897-906. doi:10.1038/onc.2011.284

15. Ambros V. The functions of animal microRNAs. Nature. 2004;431 (7006):350-355. doi:10.1038/nature02871

16. Bartel DP. MicroRNAs: genomics, biogenesis, mechanism, and function. Cell. 2004;116(2):281-297. doi:10.1016/S0092-8674(04)00045-5

17. Otoukesh B, Abbasi M, Gorgani HO, et al. MicroRNAs signatures, bioinformatics analysis of miRNAs, miRNA mimics and antagonists, and miRNA therapeutics in osteosarcoma. Cancer Cell Int. 2020;20:254.

18. Shen Z, Chai T, Luo F, et al. Loss of miR-204-5p promotes tumor proliferation, migration, and invasion through targeting YWHAZ/ PI3K/AKT pathway in esophageal squamous cell carcinoma. Onco Targets Ther. 2020;13::4679-4690. doi:10.2147/OTT.S243215

19. Yang B, Sun L. MiRNA-802 suppresses proliferation and migration of epithelial ovarian cancer cells by targeting YWHAZ. J Ovarian Res. 2019;12(1):100. doi:10.1186/s13048-019-0576-3

20. Chen M, Hu W, Xiong CL, et al. miR-22 targets YWHAZ to inhibit metastasis of hepatocellular carcinoma and its down-regulation predicts a poor survival. Oncotarget. 2016;7(49):80751-80764. doi:10.18632/oncotarget.13037

21. Jiang X, Wu J, Zhang Y, Wang S, Yu X, Li R. MiR-613 functions as tumor suppressor in hepatocellular carcinoma by targeting YWHAZ. Gene. 2018;659::168-174. doi:10.1016/j.gene.2018.03.036

22. Zhang X, Xing ND, Lai CJ, et al. MicroRNA-375 suppresses the tumor aggressive phenotypes of clear cell renal cell carcinomas through regulating YWHAZ. Chin Med J. 2018;131 (16):1944-1950. doi:10.4103/0366-6999.238153

23. Duffaud F. Role of TKI for metastatic osteogenic sarcoma. Curr Treat Options Oncol. 2020;21(8):65. doi:10.1007/s11864-020-00760-w

24. Lulla RR, Costa FF, Bischof JM, Chou PM. Identification of differentially expressed microRNAs in osteosarcoma. Sarcoma. 2011;2011:732690. doi:10.1155/2011/732690

25. Zhang W, Wei L, Sheng W, Kang B, Wang D. miR-1225-5p functions as a tumor suppressor in osteosarcoma by targeting Sox9. DNA Cell Biol. 2020;39(1):78-91. doi:10.1089/dna.2019.5105

26. Lu J, Guo H, Treekitkarnmongkol W, et al. 14-3-3zeta Cooperates with ErbB2 to promote ductal carcinoma in situ progression to invasive breast cancer by inducing epithelial-mesenchymal transition. Cancer Cell. 2009;16(3):195-207. doi:10.1016/j.ccr.2009.08.010

27. Song T, Tian X, Kai F, et al. Loss of Par3 promotes lung adenocarcinoma metastasis through 14-3-3zeta protein. Oncotarget. 2016;7 (39):64260-64273. doi:10.18632/oncotarget.11728

28. Wei GY, Hu M, Zhao L. MiR-451a suppresses cell proliferation, metastasis and EMT via targeting YWHAZ in hepatocellular carcinoma. Eur Rev Med Pharmacol Sci. 2019;23(12):5158-5167.

29. Liang R, Chen XQ, Bai QX, et al. Increased 14-3-3zeta expression in the multidrug-resistant leukemia cell line HL-60/VCR as compared to the parental line mediates cell growth and apoptosis in part through modification of gene expression. Acta Haematol. 2014;132 (2):177-186. doi:10.1159/000357377

30. Mao L, Zhang Y, Deng X, Mo W, Yu Y. Transcription factor KLF4 regulates microRNA-544 that targets YWHAZ in cervical cancer. Am $J$ Cancer Res. 2015;5(6):1939-1953.

31. Wang W, Zhang L, Wang Y, et al. Involvement of miR-451 in resistance to paclitaxel by regulating YWHAZ in breast cancer. Cell Death Dis. 2017;8(10):e3071. doi:10.1038/cddis.2017.460 
32. Wang S, Chen X, Zhang Z. MicroRNA-1225-5p inhibits the development and progression of thyroid cancer via targeting sirtuin 3 . Pharmazie. 2019;74(7):423-427.

33. Zhong R, Li S, Fang K, Yang L. microRNA-1225 inhibit apoptosis of pancreatic cancer cells via targeting JAK1. Cell Cycle. 2019;18 (9):990-1000.

34. Li D, Chi G, Chen Z. MicroRNA-1225-5p behaves as a tumor suppressor in human glioblastoma via targeting of IRS1. Onco Targets Ther. 2018;11::6339-6350. doi:10.2147/OTT.S178001
35. Sun P, Zhang D, Huang H, Yu Y, Yang Z, Niu Y. MicroRNA-1225-5p acts as a tumor-suppressor in laryngeal cancer via targeting CDC14B. Biol Chem. 2019;400(2):237-246.

36. Zheng H, Zhang F, Lin X, et al. MicroRNA-1225-5p inhibits proliferation and metastasis of gastric carcinoma through repressing insulin receptor substrate-1 and activation of beta-catenin signaling. Oncotarget. 2016;7(4):4647-4663. doi:10.18632/oncotarget.6615

\section{Publish your work in this journal}

OncoTargets and Therapy is an international, peer-reviewed, open access journal focusing on the pathological basis of all cancers, potential targets for therapy and treatment protocols employed to improve the management of cancer patients. The journal also focuses on the impact of management programs and new therapeutic

Submit your manuscript here: https://www.dovepress.com/oncotargets-and-therapy-journal agents and protocols on patient perspectives such as quality of life, adherence and satisfaction. The manuscript management system is completely online and includes a very quick and fair peer-review system, which is all easy to use. Visit http://www.dovepress.com/ testimonials.php to read real quotes from published authors. 